\title{
AC 2008-114: COOPERATIVE METHODOLOGY FOR SUCCESSFUL INTEGRATION OF UNDERGRADUATE AND GRADUATE RESEARCH PROJECTS
}

\section{James Klein, University of Idaho}

James M. Klein received the B.S. degree in electrical engineering from Oklahoma Christian University in 2005. He is currently working towards his M.S. degree in electrical engineering at the University of Idaho. His research interests include power electronics, energy storage, and electric drives.

\section{Herbert Hess, University of Idaho}

Herbert L. Hess (S'89-M'92-SM'02) received the Ph.D. degree in electrical engineering from the University of Wisconsin, Madison, in 1993. He is currently a Professor in the Department of Electrical and Computer Engineering, University of Idaho, Moscow. His research interests include power electronics, electric machines and drives, and power quality.

\section{Brian Johnson, University of Idaho}

Brian K. Johnson (M'92-SM'07) received the Ph.D. degree in electrical engineering from the University of Wisconsin, Madison, in 1992. He is currently a Professor in the Department of Electrical and Computer Engineering, University of Idaho, Moscow. His interests include HVDC transmission, FACTS, custom power technologies, energy storage, utility applications of superconductivity, power system protection, and electromagnetic transients in power systems. Dr. Johnson is a member of CIGRE and is a Professional Engineer in the states of Wisconsin and Idaho. 


\title{
Cooperative Methodology for Successful Integration of Undergraduate and Graduate Research Projects
}

\begin{abstract}
The effectiveness of integrating a structured undergraduate senior design course with the relative freedom of an individual graduate research project is presented in this paper. A cooperative methodology is outlined which serves to ensure that the project is appropriately distributed throughout the entire research team. Benefits of this team integration technique are documented and it is shown that all parties involved are rewarded accordingly. For example, the undergraduate student gains not only technical information from the graduate student, but also the opportunity to learn from a fellow engineering student who has previously completed similar senior design curriculum. The graduate student gains the ability to accomplish a greater amount of research in a shorter amount of time by paralleling project tasks through the efforts of the undergraduate students. The university benefits by providing the project sponsor with a final product that far exceeds their expectations. Along with the benefits, this paper also presents specific problems that may arise due to combining undergraduate and graduate students into a single, cohesive research team. These problems include the definition of leadership roles and an even distribution of workload. In conclusion, these problems will be shown to pale in comparison to the benefits of creating an integrated research team.
\end{abstract}

\section{Objective}

The objective of this paper is to document the potential benefits and pitfalls of integrating a senior design research project and a graduate level research project. The data and perspectives presented in this paper are a result of the first hand experience of an electrical engineering graduate student, referred to as the subject throughout this paper, who has had the opportunity to work with two different senior design teams. The main advantage of this single subject study is that the authors are able to uncover specific characteristics of the integrated research team approach without delving into generalizations where only the average viewpoint prevails ${ }^{1}$. Conversely, the results obtained from a single subject study may not properly lend themselves to accurate generalizations and should not be applied blindly to all situations. Therefore, the authors of this paper impress upon the reader the succinctness of this study.

As a point of clarity, it should be noted that the subject occupied two distinct roles within each senior design team that he worked with. For the first research project, the subject spent the first semester of the senior design course as a graduate mentor to an undergraduate research team ${ }^{2}$. At the start of the second semester of the project, the subject essentially became an additional member of the design team and was truly integrated alongside the undergraduate team members. For the second research project ${ }^{3}$, the subject served only as a graduate mentor for the senior design team and did not become as involved as in the first project. Numerous papers have been written detailing the benefits and effectiveness of graduate mentoring for senior design curriculum $^{4,5}$, as well as mentoring in general ${ }^{6,7}$. This paper is not intended to negate those findings in any way. This paper is simply intended to show that a truly integrated design team 
consisting of multiple undergraduate students and a single graduate student may hold more value than the basic mentoring approach when certain guidelines are followed.

\section{Integrating vs. Mentoring}

Before discussing the finer details of the integrated team approach, it would be beneficial to briefly consider the similarities and differences between integration and mentoring as they apply to senior design projects. In both instances, undergraduate students currently within their senior design curriculum are aided by the experience and technical knowledge of graduate students that have most likely completed a similar senior design course in the past. One distinct difference between integration and mentoring is the type of relationship that the graduate student has with the undergraduate students. In general, the integrated approach requires a closer, more in-depth relationship between the graduate student and undergraduate students than the mentoring approach. This is because a truly integrated team approach demands that the graduate student be dedicated to a single undergraduate research team, while the mentoring approach allows the graduate student to assist multiple teams. It is this simple difference that defines whether a project requires simply a graduate mentor, or whether a graduate student should be integrated within the senior design team. This simple difference also reveals the biggest drawback to an integrated research team approach. It is not uncommon for an engineering department to have more senior design teams than available graduate students. That is why it is essential to decide which projects would benefit the most from an integrated graduate student and which projects would benefit sufficiently from a graduate mentor relationship.

Due to the similarity between their implementations, the benefits of integration and mentoring at first appear to be almost identical. In both cases, the undergraduate student gains technical and non-technical information from a graduate student who has previously completed a similar senior design curriculum. The graduate student benefits from working with a design team and performing research through the undergraduate students that would not have been accomplished otherwise. These benefits are the exact same for integration and mentoring when approached from a theoretical standpoint. In reality, however, the level of benefit of a truly integrated approach will far exceed the level of benefit of a mentoring approach. The remainder of this paper will demonstrate how a properly integrated research team is able to obtain these benefits.

\section{The Driving Factor: Motivation}

Motivation is one of the largest contributors to project success ${ }^{8}$. If a student is not motivated, they will not put in the amount of time or effort that it truly takes to make a project succeed. This basic concept is why mentoring is often not as beneficial as it could be. Graduate students are expected to produce tangible results from their own independent research projects. These results may be published papers, lab models, or a polished thesis document. Regardless, the graduate student is clearly responsible for the result of their research project and that motivates the student to put in the appropriate time and effort to obtain those results. When it comes to mentoring, however, a graduate student does not have that direct correlation of effort and result. A graduate student may technically be responsible for mentoring multiple senior design teams, but the reality is that those teams may never even have a single conversation with the graduate student. Our subject offers two reasons why this ineffective mentor relationship might occur. If 
the graduate student is assigned to the mentoring role by a third party, the personal research interest of the student may not necessarily match the topic of the senior design project.

Secondly, even if the graduate student is interested in the senior design research topic, their own coursework and thesis research obligations create time conflicts with the senior design project. Since the graduate student is more directly responsible for their coursework and thesis research, the needs of the senior design project often get set aside. Despite the actual cause of this ineffective mentor relationship, the end result is that the graduate student is simply not motivated to help the senior design team. In these cases, the undergraduate students must actively seek out the graduate mentor and ask for help. More often than not, the undergraduate students choose to seek out their faculty advisor in these situations and the benefits of a graduate mentor are completely lost.

Integration is one simple way to solve this motivation problem. As stated previously, the integrated team approach demands that the graduate student maintain a closer relationship with the senior design team than a mentoring role entails. This is best accomplished by ensuring that the graduate student has vested interest in the undergraduate research project. For the case of our subject, the topic of the senior design research project was a direct match for his thesis research interest. By combining the role of graduate mentor with the future task of a thesis research project, the proper motivation for an integrated research team was created. The subject delved into the senior design project with the thought that any research left unfinished at the end of the project would fall onto his shoulders. It is this type of motivation and responsibility that is lacking from graduate mentor relationships.

\section{Leadership and Team Dynamics}

Aside from deciding whether or not the integrated team approach is the right choice for a certain project, there are a few other considerations that must be discussed. Proper division of labor and the definition of team roles are two of the greatest challenges to overcome within any research project $^{9}$. Normally, a senior design team consists of multiple undergraduate students who are relatively equal to each other in terms of technical knowledge and research experience. When a graduate student who has already completed a previous senior design project is thrown into the mix, the undergraduate students may tend to look to the graduate student as the team leader and an inappropriate division of labor may occur. This is most likely to occur if the graduate student is integrated into the senior design team from the onset of the project. It is during the first few weeks of the project, normally a time filled with non-technical tasks that may be completely new to the undergraduate students, that a team leader must emerge. This leader may be officially appointed by faculty members, chosen by the undergraduate students themselves, or simply emerge through natural team dynamics. Which ever way the team leader is defined at the onset of the project, it is essential that the team leader is not the graduate student. The goal of an integrated research team is to benefit all parties involved. If the graduate student is seen as the team leader from the beginning of the project, the undergraduate students are more likely to lose some of the valuable experience and learning situations that the senior design curriculum offers them. Also, the graduate student may become overloaded with the combination of technical tasks and team leadership responsibilities. Overall, the project outcome and all those involved will most likely suffer, rather than benefit, from an integrated approach if the graduate student is relied upon too heavily. To avoid this situation, it is suggested that the graduate student occupy 
an initial role of mentor to the senior design team. This allows the senior design team to define their own roles and not rely upon the graduate student more than they should. The graduate student may then be integrated into the team at a later point in time in such a way as to not disrupt the established team dynamics.

As stated previously, the subject of this study began as a graduate mentor to the team that he would later become integrated with. This was not done intentionally, but was simply due to the fact that the subject had a prior commitment as a teacher's assistant for the first semester of the senior design project. It was not until the project was completed that the benefits of this integration approach were realized. By starting the project with a graduate mentor, instead of a graduate student team member, the undergraduate students were able to define their own team roles and create a proper division of labor amongst themselves. Accordingly, one of the undergraduate students was chosen as the team leader and the subject simply helped out where needed during this period of time. During the initial stages of the project, the subject was able to provide the undergraduate students enough freedom to learn on their own while also providing enough direction to effectively move the project forward. The role of a true graduate mentor is ideal for accomplishing this type of guidance. By allowing the senior design team to complete such tasks as problem definition and project scheduling, essentially on their own, the undergraduate students effectively decided the level and type of design work that they would be undertaking. This method of integration ensures that the design aspect of the senior design project is not taken away from the undergraduate students.

\section{From Mentor to Team Member}

The transition time from graduate mentor to integrated team member is something that must be decided on a project by project basis. It is suggested that following the initial planning phase of the senior design project, the graduate student may be integrated into the team in order to help with the burden of initial research and solution development. However, one essential consideration for when this transition should take place is the amount of time that the graduate student will be able to dedicate to the senior design project. If the graduate student is currently committed to other projects and would not be able to increase the amount of time he spends on the senior design project, the graduate student should simply remain on as a mentor. Defining the graduate student as an additional team member while still maintaining a cursory relationship with the rest of the design team may produce animosity from the undergraduate students toward the graduate student.

It is suggested that the best opportunity to increase the role of the graduate student from mentor to team member would be at the beginning of the second semester of the senior design project. This was the case for our subject and it proved to be a relatively smooth transition. The subject no longer had a teaching assistantship obligation and was therefore able to devote a considerable amount of time to the research project. Also, the undergraduate students had accomplished a large enough amount of work over the previous semester that they could clearly see what needed to be done for the remainder of the project to succeed. The addition of a new team member, one who was already familiar with the project and its goals, provided a greater amount of hope that the remaining tasks could actually be accomplished. With team roles already defined for the undergraduate students, the subject was relatively free to define what area of the project to focus 
on. This freedom to delve deeper into a certain area of the project is one of the greatest benefits of this integrated team approach for the graduate student.

\section{Project Conclusion}

Through the addition of the graduate student, the outcome of the senior design project is more likely to succeed. This is not because the graduate student steps in and takes over the project, but simply due to the fact that the graduate student is able to increase the effectiveness of the entire senior design team. Throughout the course of a senior design project, undergraduate students often find themselves facing problems that they either feel are too insignificant to bring before their advisor, or their advisor may simply be unable to help due to other obligations. The reality of these types of problems is that the research project is effectively put on hold until the problem is resolved. It is during these times that the integrated graduate student is able to boost the senior design team over their hurdle. This is one of the goals of graduate mentoring, but it is much more easily accomplished when the graduate student is actually a working part of the design team. The undergraduate students do not have to seek out the graduate student and explain the problem they are having. The integrated graduate student is likely able to address the problem as it arises, not hours or days later. It is this intimate relationship between the graduate student and the senior design team that causes the project to progress much more rapidly than in a normal mentoring relationship. Therefore, the university benefits from this integrated team approach by demonstrating to the project sponsor the successful result of their senior design project.

In many cases, the project will not be completely finished by the end of the senior design curriculum. The project may have produced detailed documentation, a scaled model, or even a working prototype, but the university and/or the project sponsor may want the result of the project to be further refined. Regardless, the graduate student that was part of the initial senior design project will most likely need to continue to work on the project in order to produce his thesis. If a second senior design team is tasked with the continuation of the project, the graduate student can greatly aid the undergraduate students through the same mentor to team member relationship outlined in this paper.

In the specific case of our subject, the result of the senior design project was a documented solution with a scaled lab model demonstration. The senior design course finished at the end of the spring semester, but the sponsor of the project continued the funding of the project for a single graduate student over the summer. The subject was then able to transition the project from a senior design project to an independent graduate research project smoothly and effectively. The wealth of information that was gathered and documented during the senior design project greatly helped the subject produce a redesigned solution without having to unnecessarily retrace design steps. The integrated team approach ensures that the graduate student is able to effectively carry-on the research project after the initial senior design team has completed its work.

\section{Summary}

The objective of the integrated research team approach is to benefit all of the parties involved in a senior design project. It has been shown that the integrated approach provides a greater level 
of benefit than the more commonly used mentoring approach, but that the integrated approach should only be used when the content of the research project warrants it and the graduate student is able to dedicate the proper amount of time to the project. The proper motivation must exist for the graduate student to be truly integrated into the senior design project. It is suggested that this be accomplished by aligning the graduate student's thesis research interest with the senior design research topic. With an integrated team approach, steps must be taken to ensure that the design aspect of the senior design project is not taken away from the undergraduate students. For this reason, it is suggested that the graduate student initially occupy a role of graduate mentor before becoming a member of the design team. It is strongly suggested that the defined team leader role of the senior design team be occupied by an undergraduate student and that the graduate student should later find a role within the team that does not disturb the existing team dynamic. When these guidelines are followed, the integrated research team approach will produce results beyond what is expected and all parties involved will benefit greatly from the experience.

\section{Bibliography}

1. Franza, R.M. and Chakravorty, S.S., "Design for six sigma (dfss): a case study," Management of Engineering Technology, Portland International Center for, pp. 1982-1989, Aug. 2007.

2. Byrne, Chris. "Maritime Energy Management Systems," http://seniordesign.engr.uidaho.edu/2006_2007/cutthroatenergy, Jan 2008

3. Lundgren, Dirk. “Team QuEST,” http://seniordesign.engr.uidaho.edu/2007_2008/quest, Jan 2008

4. Odom, E.M., et al. "Idaho engineering works: a model for leadership development in design education," Frontiers in Education Conference, $29^{\text {th }}$ Annual, Vol. 1, pp. 11B2/21-11B2/24, Nov 1999

5. Johnson, T.A., et al. "Senior design in the setting of multidisciplinary research," International Journal of Engineering Education, vol. 23, no. 3, pp. 570-581, 2007

6. Marszalek, M.A., et al. "Mentors improve the college experience of engineering undergraduates," Frontiers in Education Conference, $35^{\text {th }}$ Annual, pp. F2G-10 - F2G-13, Oct 2005

7. Hoschette, J.A. “A mentor in hand,” IEEE Spectrum, vol. 32, no. 2, pp. 56-58, Feb 1995

8. Babcock, D.L. and Morse, L.C., Managing Engineering and Technology, 3d ed. New Jersey: Prentice Hall, 2002, pp. 138

9. Mochizuki, T., et al. "A design of self-assessment environment in project-based learning: monitoring and reorganizing tasks and division of labor," Information Technology Based Higher Education and Training, $6^{\text {th }}$ International Conference on, pp. F2D/1-F2D/6, July 2005. 